\title{
Three-dimensional intraoperative computed tomography imaging for zygomatic fracture repair
}

\author{
Oren Peleg ${ }^{1}$, Clariel Ianculovici ${ }^{1}$, Amir Shuster ${ }^{1,2}$, Eitan Mijiritsky ${ }^{1}$, Itay Oz ${ }^{1, *}$, Shlomi Kleinman ${ }^{1, *}$ \\ ${ }^{I}$ Department of Otolaryngology Head and Neck Surgery and Maxillofacial Surgery, \\ Tel Aviv Sourasky Medical Center, Sackler School of Medicine, Tel Aviv University, \\ ${ }^{2}$ Department of Oral and Maxillofacial Surgery, Goldschleger School of Dental Medicine, Tel Aviv University, Tel Aviv, Israel
}

\begin{abstract}
J Korean Assoc Oral Maxillofac Surg 2021;47:382-387)
Objectives: Zygomatic complex (ZMC) fractures comprise up to $40 \%$ of all facial fractures. Misaligned bone fragments and misplaced fixation hardware traditionally detected postoperatively on plain radiographs of the skull might require re-operation. The intraoperative O-Arm (Medtronic, USA) is a three-dimensional (3D) computed tomographic imaging system.

Materials and Methods: This retrospective single-center study evaluated the utility of O-Arm scanning during corrective surgeries for ZMC and zygomatic arch (ZA) fractures from 2018 to 2020. Three females and 16 males (mean age, 31.52 years; range, 22-48 years) were included. Fracture instability $(\mathrm{n}=6)$ and facial deformity $(\mathrm{n}=15)$ were the most frequent indications for intraoperative 3D O-Arm scan.

Results: The images demonstrated that all fracture lines were properly reduced and fixed. Another scan performed at the end of the fixation or reduction stage, however, revealed suboptimal results in five of the 19 cases, and further reduction and fixation of the fracture lines were required.

Conclusion: Implementation of an intraoperative O-Arm system in ZMC and ZA fracture surgeries assists in obtaining predictable and accurate results and obviates the need for revision surgeries. The device should be considered for precise operations such as ZMC fracture repairs.
\end{abstract}

Key words: Zygomatic fractures, Maxillofacial injury, Maxillofacial procedure, X-ray computed tomography, CT X ray

[paper submitted 2021. 3. 6 / revised 1st 2021. 5. 2, 2nd 2021. 6. 10 / accepted 2021. 6. 28]

\section{Introduction}

Fractures of the zygoma and surrounding bones are common facial bone fractures and are likely the most common type of orbital fractures ${ }^{1}$. Zygomatic complex (ZMC) fractures account for $40 \%-57 \%$ of facial fractures, while zygomatic arch (ZA) fractures account for $10.5 \%-13.8 \% \%^{2-5}$. The four articulations of the zygoma with the adjacent facial bones (sphenoid, frontal, temporal, and maxilla) have aesthetic significance for restoration of facial width and lateral

\section{Oren Peleg}

Department of Otolaryngology Head and Neck Surgery and Maxillofacial Surgery, Tel Aviv Sourasky Medical Center, 6 Weizman Street, Tel Aviv 6423906, Israel

TEL: $+972-54-4636691$

E-mail: orenpeleg@gmail.com

ORCID: https://orcid.org/0000-0001-9220-4462

*These authors contributed equally to this work.

(c) This is an open-access article distributed under the terms of the Creative Commons Attribution Non-Commercial License (http://creativecommons.org/ licenses/by-nc/4.0/), which permits unrestricted non-commercial use, distribution, and reproduction in any medium, provided the original work is properly cited.

Copyright (C) 2021 The Korean Association of Oral and Maxillofacial Surgeons. projection of the face. The multiaxis structures of both ZMC and orbitozygomatic region fractures pose challenges to surgeons in assessment and proper reduction. Postoperative plain radiographs of the skull, such as Waters and submentovertex views, are used traditionally to evaluate reduction of bony segments following ZMC fracture repair, ${ }^{6,7}$.

Patients who sustain ZMC and ZA fractures can present with a wide variety of signs and symptoms, such as periorbital hematoma, sensory alterations in cranial nerve $\mathrm{V}$ facial skin spread, pain, restriction of eyeball movement due to muscle entrapment within fracture lines, limited opening of the mouth, and facial deformity ${ }^{1,2-4,8}$. The signs and symptoms of these fractures are related to the specific fracture site. For example, if the ZA is depressed medially, interference with the movement of the coronoid process can cause limited mouth opening, since the coronoid process strikes the depressed malar eminence as it moves forward during jaw opening $^{1,9}$. Loss of prominence of the malar eminence is a frequent sequela of ZMC fractures, and it can be concealed by soft tissue swelling during the first days following trau$\mathrm{ma}^{10}$. The lateral canthal ligament attaches to the frontal pro- 
cess of the zygoma and can be displaced in ZMC fractures ${ }^{11}$. Inferior and posterior displacements of the zygoma produce varying degrees of increased or decreased volumes of the orbital cavity $^{12}$. Diplopia can be present due to entrapment of the orbital muscles within the fracture lines, and fractures of the infraorbital rim can lead to sensory impairment due to an infraorbital nerve injury ${ }^{8}$. The sphenozygomatic (SZ) junction is an important landmark in $\mathrm{ZMC}$ fracture reduction. The alignment of the zygoma with the greater wing of the sphenoid in the lateral orbit is critical for adequate reduction of $\mathrm{ZMC}$ fractures ${ }^{13}$.

Several imaging techniques for ZMC fractures have been mentioned in the literature. The submentovertex view allows the ZA contour and malar projection to be evaluated. However, it can be challenging for the operating surgeon to assess the maxillozygomatic (MZ), SZ, and frontozygomatic articulations due to the effects of superimpositions between adjacent anatomical structures and the imaging plane. Moreover, adequate assessment of the orbital floor is not possible on plain radiographs due to the same limitations ${ }^{14}$. Intraoperative ultrasonography (US) offers good visualization of the ZA and possibly the frontozygomatic articulation; however, the $\mathrm{MZ}$ and $\mathrm{SZ}$ articulations are more difficult to visualize, and malar projections cannot be assessed with US. Assess- ment of the orbital floor is possible with US, but the accuracy is lower than with a computed tomographic (CT) scan ${ }^{15,16}$. In contrast to these approaches, intraoperative three-dimensional (3D) imaging is an effective tool for evaluating ZMC fracture reduction because it enables a $3 \mathrm{D}$ evaluation of all the articulations and eliminates the need for postoperative imaging $^{13}$. Intraoperative imaging with mobile CT systems during corrective surgeries for ZMC fractures has been described with promising results, although this approach has not been accepted broadly ${ }^{17-19}$ due to limited availability and practical limitations ${ }^{14}$. The O-Arm (Medtronic, Littleton, MA, USA) is a mobile X-ray system designed for 2D fluoroscopy and $3 \mathrm{D}$ imaging, with high X-ray attenuation between bone anatomy and metallic objects.

The purpose of this study was to evaluate the utility of intraoperative 3D imaging using the O-Arm system as an approach for routine use in $\mathrm{ZMC}$ and $\mathrm{ZA}$ corrective surgeries.

\section{Materials and Methods}

This retrospective study included consecutive patients who had sustained ZMC or ZA fracture and were planning to undergo corrective surgery in the Department of Oral and Maxillofacial Surgery at Tel Aviv Sourasky Medical Center, Tel

Table 1. Distribution of age, sex, mechanism of injury, fracture type, surgical repair approach, need for a revision reduction, maximal correction error and location

\begin{tabular}{|c|c|c|c|c|c|c|c|c|}
\hline $\begin{array}{l}\text { Patient } \\
\text { No. }\end{array}$ & Age (yr) & Sex & $\begin{array}{l}\text { Mechanism } \\
\text { of injury }\end{array}$ & $\begin{array}{l}\text { Fracture } \\
\text { type }\end{array}$ & $\begin{array}{l}\text { Surgical } \\
\text { approach }\end{array}$ & $\begin{array}{l}\text { Revision } \\
\text { reduction }\end{array}$ & $\begin{array}{l}\text { Maximal } \\
\text { correction } \\
\text { error }(\mathrm{mm})\end{array}$ & $\begin{array}{c}\text { Location } \\
\text { of maximal } \\
\text { correction error }\end{array}$ \\
\hline 1 & 28 & $\mathrm{M}$ & Assault & Left ZMC & Intraoral and lateral eyebrow & No & +9 axial & $\mathrm{MZ}$ \\
\hline 2 & 27 & M & Road accident & Right ZMC & $\begin{array}{l}\text { Transconjunctival and lateral } \\
\text { eyebrow }\end{array}$ & No & 0 & None \\
\hline 3 & 31 & M & Fall & Right ZMC & Coronal & No & +8 axial & SZ \\
\hline 4 & 36 & M & Fall & Right ZMC & Intraoral and lateral eyebrow & No & -1 axial & $\mathrm{MZ}$ \\
\hline 5 & 27 & $\mathrm{~F}$ & Road accident & Left ZMC & Intraoral & No & +6 axial & SZ \\
\hline 6 & 30 & M & Fall & Right ZA & Gillies & No & 0 & None \\
\hline 7 & 30 & M & Road accident & Right ZMC & Intraoral & No & +2 axial & $\mathrm{MZ}$ \\
\hline 8 & 29 & M & Fall & Left ZMC & Gillies & No & +1 axial & $\mathrm{ZA}$ \\
\hline 9 & 23 & $\mathrm{~F}$ & Assault & Left ZMC & $\begin{array}{l}\text { Intraoral, transconjunctival, } \\
\text { and lateral eyebrow }\end{array}$ & Yes & -1 axial & $\mathrm{ZA}$ \\
\hline 10 & 23 & M & Road accident & Left ZA & Gillies incision & Yes & +3 axial & $\mathrm{ZA}$ \\
\hline 11 & 26 & M & Road accident & Right ZMC & Intraoral and lateral eyebrow & No & +2 axial & MZ \\
\hline 12 & 34 & M & Road accident & Left ZMC & $\begin{array}{l}\text { Transconjunctival,Gillies, and } \\
\text { lateral eyebrow }\end{array}$ & Yes & +4 axial & $\mathrm{SZ}$ \\
\hline 13 & 31 & M & Sport accident & Left ZMC & $\begin{array}{l}\text { Transconjunctival and lateral } \\
\text { eyebrow }\end{array}$ & No & 0 & None \\
\hline 14 & 40 & M & Road accident & Right ZMC & Intraoral & Yes & +2 axial & $\mathrm{ZA}$ \\
\hline 15 & 22 & $\mathrm{~F}$ & Road accident & Right ZMC & Intraoral & No & 0 & None \\
\hline 16 & 27 & M & Road accident & Right ZMC & Lateral eyebrow & No & -1 axial & ZA \\
\hline 17 & 32 & M & Road accident & Left ZMC & Intraoral and lateral eyebrow & No & +6 axial & Zygoma body \\
\hline 18 & 48 & M & Road accident & Left ZMC & Gillies and lateral eyebrow & No & +2 axial & $\mathrm{ZA}$ \\
\hline 19 & 42 & $\mathrm{M}$ & Road accident & Right ZMC & Lateral eyebrow & Yes & -2 axial & $\mathrm{ZA}$ \\
\hline
\end{tabular}

(M: male, F: female, ZMC: zygomatic complex, MZ: maxillozygomatic, SZ: sphenozygomatic, ZA: zygomatic arch)

Oren Peleg et al: Three-dimensional intraoperative computed tomography imaging for zygomatic fracture repair. J Korean Assoc Oral Maxillofac Surg 2021 
Aviv, Israel, from 2018 to 2020. Ethical application was submitted to the Helsinki Ethics Committee, and approval was obtained on 11/11/2020 (0970-20-TLV). Preoperative clinical evaluation and facial bone $\mathrm{CT}$ scans were performed in the emergency room as part of the institutional trauma protocol.

Lateral eyebrow, transconjunctival, coronal, and intraoral approaches were used as appropriate to explore and fix the various fracture lines. The Gillis approach was used to reduce ZA fractures. The inferior orbital rim was reconstructed with $1.5 \mathrm{~mm}$ microplates. ZMC buttresses were reconstructed with $2.0 \mathrm{~mm}$ miniplates. Radiographic evaluation of the reduction was performed intraoperatively before wound closure, and the O-Arm system was used in the low-dose mode with a CT dose index of $19.78 \mathrm{mGy} \mathrm{cm}$, a dose length product of $316 \mathrm{mGy} \mathrm{cm}$, and a slice thickness of $0.6-1.0 \mathrm{~mm}$. The patient's head was placed in alignment with the isocenter beam (i.e., the central axis of the radiation beam that passes through a single point in space) that was marked with assistance from a laser marker, and a single fluoroscopic image was produced to ensure that the scan would cover the entire desired field.

The operative results were verified with secondary imaging reconstructions generated with the O-Arm program. After the scan, the data were exported in DICOM format and imported into the patient's medical file. Primary axial reconstruction and secondary pseudo-coronal and pseudo-sagittal reconstructions were generated. The scan was evaluated for fracture line reduction, ZMC and ZA symmetry, accuracy of fixation, and orbital shape and volume in comparison to the opposite side. Repair deviations from the side that did not undergo operation were recorded in $\mathrm{mm}$, as was the location of the maximal deviation.

\section{Results}

Nineteen patients with ZMC fractures ( $\mathrm{n}=17)$ or $\mathrm{ZA}$ fractures $(n=2)$ were treated for zygoma fracture repair. Three patients underwent a closed reduction alone, and 16 underwent an open reduction and internal fixation. The inferior orbital rim was reconstructed in four ZMC cases. The distributions of patient age, sex, mechanism of injury, fracture type, surgical repair approach, need for revision reduction, and maximal repair deviation and location are summarized in Table 1 . The male-to-female ratio was $16: 3$, and the patients' ages ranged from 22 to 48 years (mean age, 31.5 years).

The intraoperative handling of the system was safe and uncomplicated. On average, patient covering, scanner laser alignment, scan process, machine removal, and data evalua-
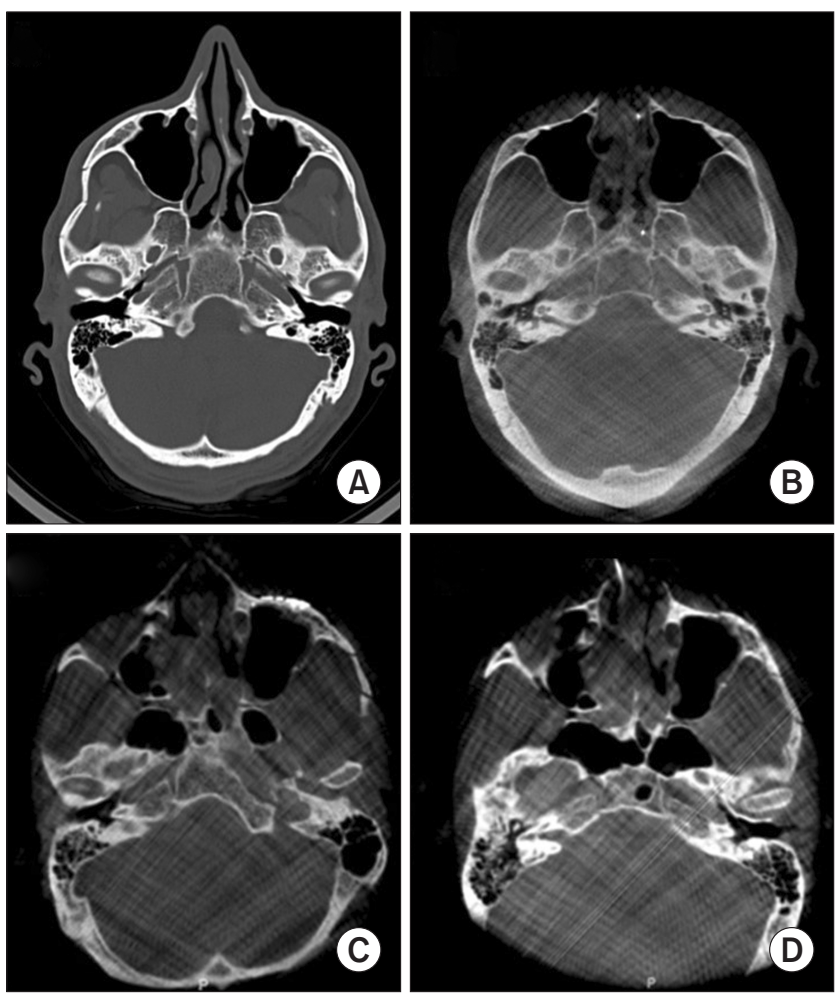

Fig. 1. A composite figure presenting two clinical cases. Case No. 1: a preoperative computed tomographic scan demonstrating a right zygomatic arch fracture (A) followed by an intraoperative O-Arm scan that demonstrates an adequate reduction of the zygomatic arch fracture (B). Case No. 2: an insufficient reduction of a left zygomatic complex (ZMC) fracture as demonstrated in an intraoperative O-Arm scan (C), and a second intraoperative OArm scan following the correction of the reduction and fixation of the left ZMC fracture lines (D).

Oren Peleg et al: Three-dimensional intraoperative computed tomography imaging for zygomatic fracture repair. J Korean Assoc Oral Maxillofac Surg 2021

tion took 16 minutes. One dataset was sufficient to visualize intraoperatively all fractures for each of the patients. The 3D scan revealed inadequate reduction in five patients, and realignment of the fracture was performed with satisfactory results for all five of them. In all cases, one additional O-Arm scan was sufficient to confirm a satisfactory correction. None of the 19 cases required a revision surgery. The datasets for all of the O-Arm scans were suitable for assessing the ZMC and ZA fracture reductions.(Fig. 1,2)

\section{Discussion}

Zygoma fractures can impact clinical outcomes and can compromise functional ability and esthetic facial appearance. In their comprehensive study, Kim et al. ${ }^{7}$ compared soft tissue differences over repaired zygoma fractures using cephalometric points measured in cone-beam CT scans. They found soft tissue asymmetry that was directly related to the 

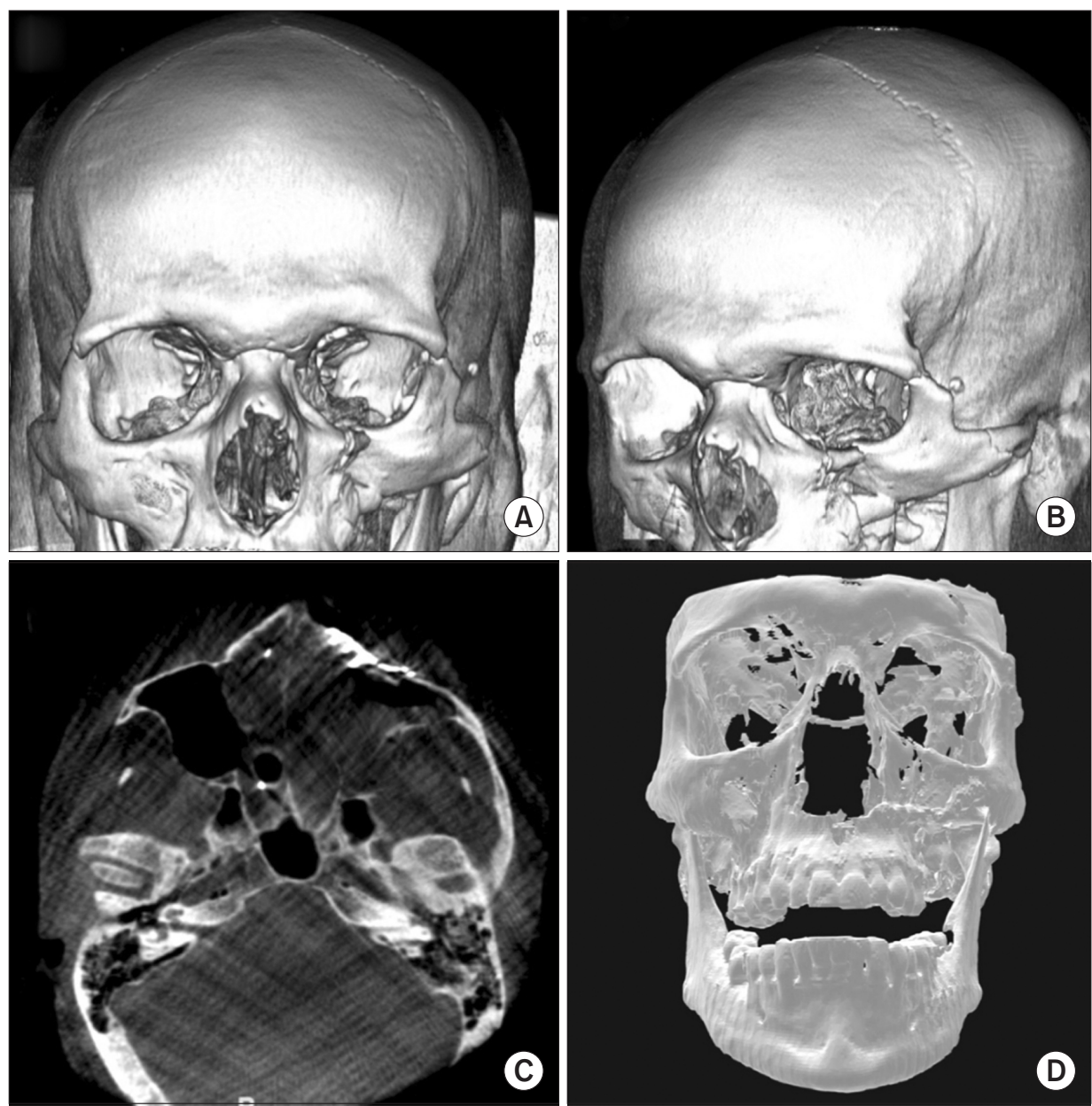

Fig. 2. A composite figure presenting another case: a preoperative threedimensional (3D) reconstruction computed tomographic scan demonstrates a left zygomatic complex fracture $(A$, B) followed by an intraoperative O-Arm scan that demonstrates a proper reduction and fixation of the zygomatic complex fracture $(C)$, and a $3 D$ reconstruction of the same intraoperative O-Arm scan presenting a good clinical result (D). Oren Peleg et al: Three-dimensional intraoperative computed tomography imaging for zygomatic fracture repair. J Korean Assoc Oral Maxillofac Surg 2021

amount of hard tissue dislocated after surgery. Management of ZMC and ZA fracture can be challenging due to the difficulties with clinical evaluation of the extent of the injury due to facial edema, periorbital hematoma, and poor patient cooperation due to pain. The reduction and fixation stages during the surgery also can be challenging due to the complicated $3 \mathrm{D}$ structures of ZMC and ZA fractures and the effects on facial symmetry, orbital content anatomy and function, and mouth opening. An intraoperative imaging system would allow surgical results to be visualized before wound closure. In the present study, the O-Arm system was a highly successful approach for visualization and could minimize the need for revision interventions following the initial $\mathrm{ZMC}$ and $\mathrm{ZA}$ corrective surgeries.

Plain radiographs of the skull, such as the Waters view, the submentovertex view, and lateral radiographs to evaluate intraoperatively ZMC and ZA fracture reconstruction are used frequently ${ }^{6,7}$. However, the resolution of these images and the superimpositions with adjacent bony structures, especially in the region of the orbital walls, can result in inadequate surgi- cal results. Orbital wall involvement in ZMC fractures cannot be ruled out, and 3D imaging is superior for detecting and evaluating the surgical result ${ }^{11}$. Systems such as the O-Arm can help facilitate the adoption of minimally invasive surgical techniques by providing intraoperative 3D imaging findings and thereby improving the accuracy of the surgical intervention and outcome, while decreasing surgery time, reducing patient morbidity, and saving money. The O-Arm system has been used extensively in spinal neurosurgery, orthopedic surgery, skull base surgery, intracranial surgery, and trauma surgery, as well as minimally invasive interventions ${ }^{20}$. Intraoperative imaging, such as US, spiral CT, and cone beam CT, revealed the need for additional reduction of $\mathrm{ZMC}$ fractures in up to $54 \%$ (mean, 18\%) of cases ${ }^{14}$. Intraoperative use of an US alone was associated with a revision rate of $54 \% 6$.

The radiation dose can be a pivotal issue in clinical application of imaging studies. According to Sarwahi et al. ${ }^{21}$, the effective radiation doses for the O-Arm vary between 0.68 $2.1 \mathrm{mSv}$ depending on the imaging protocol. Verhofste et al. ${ }^{22}$ claim that the mean effective radiation dose for the O-Arm 
scans is $1.57 \pm 0.818 \mathrm{mSv}$. These values are larger than the effective radiation doses of skeletal plain radiographs $(0.03-0.22$ $\mathrm{mSv})^{23}$ but smaller or equal to those of a head CT scan (1.05$2.16 \mathrm{mSv})^{21}$.

The 3D O-Arm scan combines a more accurate and informative $3 \mathrm{D}$ image than that provided by $2 \mathrm{D}$ plain radiographs, at the price of slightly higher amounts of radiation, if more than one plain radiograph is needed to evaluate the surgical outcome. The preferential use of the 3D O-Arm scan is in agreement with Stanley's finding ${ }^{19}$ and Wilde et al.'s finding $^{24}$. With regard to patient satisfaction, Kurita et al. ${ }^{25}$ reported that $43 \%$ of the patients were dissatisfied with the projection of the zygoma and the aesthetic result. An additional surgical maneuver was needed during the surgery in five of the 19 study patients (26.3\%) following the information provided by the intraoperative O-Arm scan, and revision surgery was avoided. In contrast to the traditional postoperative imaging studies, the intraoperative O-Arm scan was instrumental for achieving a more accurate and predictable surgical outcome. Further, physicians and patients should consider the personal harm to patients associated with poor surgical outcomes, and the financial burden placed upon hospitals when a revision surgery for ZMC and ZA fractures is required cannot be underestimated. Using an intraoperative 3D O-Arm imaging system, reduction of the ZMC and ZA fractures can be assessed in real time, enabling immediate intervention if indicated and avoiding the need for a second surgical intervention and facilitating more predictable and accurate outcomes. The intraoperative 3D O-Arm scan is highly beneficial in ZMC and ZA corrective surgeries, which are difficult technically to execute for the operating surgeon and which have critically important functional and aesthetic ramifications for the patients.

\section{Conclusion}

Implementation of an intraoperative O-Arm system in $\mathrm{ZMC}$ and ZA fracture surgeries assists in obtaining predictable and accurate results and obviates the need for revision surgeries. The device should be considered for precise operations such as ZMC fracture repairs.

\section{ORCID}

Oren Peleg, https://orcid.org/0000-0001-9220-4462

Clariel Ianculovici, https://orcid.org/0000-0003-3610-6512

Amir Shuster, https://orcid.org/0000-0002-5057-8623
Eitan Mijiritsky, https://orcid.org/0000-0002-1661-7529

Itay Oz, https://orcid.org/0000-0003-1274-9767

Shlomi Kleinman, https://orcid.org/0000-0001-5288-7668

\section{Authors' Contributions}

O.P. participated in data collection, study design, and wrote the article. C.I. participated in data collection and study design. A.S. participated in study design and article draft, and statistical analysis. E.M. participated in study design, coordination and statistical analysis. I.O. participated in data collection, study design, and wrote the article. S.K. participated in data collection, coordination and study design.

\section{Ethics Approval and Consent to Participate}

Ethical application was submitted to the Helsinki Ethics Committee, and approval was obtained on 11/11/2020 (097020-TLV). Informed consent was obtained from all patients.

\section{Conflict of Interest}

No potential conflict of interest relevant to this article was reported.

\section{References}

1. Kelley P, Hopper R, Gruss J. Evaluation and treatment of zygomatic fractures. Plast Reconstr Surg 2007;120(7 Suppl 2):5S-15S. https://doi.org/10.1097/01.prs.0000260720.73370.d7

2. Bogusiak K, Arkuszewski P. Characteristics and epidemiology of zygomaticomaxillary complex fractures. J Craniofac Surg 2010;21:1018-23. https://doi.org/10.1097/scs.0b013e3181e62e47

3. Marinho RO, Freire-Maia B. Management of fractures of the zygomaticomaxillary complex. Oral Maxillofac Surg Clin North Am 2013;25:617-36. https://doi.org/10.1016/j.coms.2013.07.011

4. Gomes PP, Passeri LA, Barbosa JR. A 5-year retrospective study of zygomatico-orbital complex and zygomatic arch fractures in Sao Paulo State, Brazil. J Oral Maxillofac Surg 2006;64:63-7. https:// doi.org/10.1016/j.joms.2005.09.012

5. Adam AA, Zhi L, Bing LZ, Zhong Xing WU. Evaluation of treatment of zygomatic bone and zygomatic arch fractures: a retrospective study of 10 years. J Maxillofac Oral Surg 2012;11:171-6. https://doi.org/10.1007/s12663-011-0294-x

6. Gülicher D, Krimmel M, Reinert S. The role of intraoperative ultrasonography in zygomatic complex fracture repair. Int $\mathrm{J}$ Oral Maxillofac Surg 2006;35:224-30. https://doi.org/10.1016/ j.ijom.2005.10.005

7. Kim JS, Park YJ, Lee YJ, Kim NG, Lee KS. Reduction of zygomatic arch isolated fracture using ultra sound and needle marking. Arch Craniofac Surg 2016;17:198-201. https://doi.org/10.7181/ acfs.2016.17.4.198

8. Ellis E 3rd, Perez D. An algorithm for the treatment of isolated zygomatico-orbital fractures. J Oral Maxillofac Surg 2014;72:197583. https://doi.org/10.1016/j.joms.2014.04.015 
9. Ostrofsky MK, Lownie JF. Zygomatico-coronoid ankylosis. J Oral Surg 1977;35:752-4.

10. Khaqani MS, Tavosi F, Gholami M, Eftekharian HR, Khojastepour L. Analysis of facial symmetry after zygomatic bone fracture management. J Oral Maxillofac Surg 2018;76:595-604. https://doi. org/10.1016/j.joms.2017.10.005

11. Manson PN, Clifford CM, Su CT, Iliff NT, Morgan R. Mechanisms of global support and posttraumatic enophthalmos: I. The anatomy of the ligament sling and its relation to intramuscular cone orbital fat. Plast Reconstr Surg 1986;77:193-202.

12. Barry C, Coyle M, Idrees Z, Dwyer MH, Kearns G. Ocular findings in patients with orbitozygomatic complex fractures: a retrospective study. J Oral Maxillofac Surg 2008;66:888-92. https://doi. org/10.1016/j.joms.2008.01.005

13. Maheedhar AV, Ravindran C, Azariah ED. Use of C-arm to assess reduction of zygomatic complex fractures: a comparative study. Craniomaxillofac Trauma Reconstr 2017;10:35-43. https://doi. org/10.1055/s-0036-1592085

14. van Hout WM, Van Cann EM, Muradin MS, Frank MH, Koole R. Intraoperative imaging for the repair of zygomaticomaxillary complex fractures: a comprehensive review of the literature. J Craniomaxillofac Surg 2014;42:1918-23. https://doi.org/10.1016/ j.jcms.2014.07.012

15. Jank S, Deibl M, Strobl H, Oberrauch A, Nicasi A, Missmann M, et al. Interrater reliability of sonographic examinations of orbital fractures. Eur J Radiol 2005;54:344-51. https://doi.org/10.1016/ j.ejrad.2004.07.009

16. Jenkins $\mathrm{CN}$, Thuau $\mathrm{H}$. Ultrasound imaging in assessment of fractures of the orbital floor. Clin Radiol 1997;52:708-11. https://doi org/10.1016/s0009-9260(97)80037-2

17. Hoelzle F, Klein M, Schwerdtner O, Lueth T, Albrecht J, Hosten $\mathrm{N}$, et al. Intraoperative computed tomography with the mobile CT Tomoscan $\mathrm{M}$ during surgical treatment of orbital fractures. Int J Oral Maxillofac Surg 2001;30:26-31. https://doi.org/10.1054/ ijom.2000.0014

18. Hoffmann J, Krimmel M, Dammann F, Reinert S. [Feasibility of intraoperative diagnosis with a mobile computed tomography scanner]. Mund Kiefer Gesichtschir 2002;6:346-50. German. https:/ doi.org/10.1007/s10006-002-0406-3

19. Stanley RB Jr. Use of intraoperative computed tomography during repair of orbitozygomatic fractures. Arch Facial Plast Surg 1999;1: 19-24. https://doi.org/10.1001/archfaci.1.1.19

20. Uneri A, Zhang X, Yi T, Stayman JW, Helm PA, Theodore N, et al Image quality and dose characteristics for an O-arm intraoperative imaging system with model-based image reconstruction. Med Phys 2018;45:4857-68. https://doi.org/10.1002/mp.13167

21. Sarwahi V, Payares M, Wendolowski S, Maguire K, Thornhill $\mathrm{B}$, Lo $\mathrm{Y}$, et al. Low-dose radiation $3 \mathrm{D}$ intraoperative imaging: how low can we go? An O-arm, CT scan, cadaveric study. Spine (Phila Pa 1976) 2017;42:E1311-7. https://doi.org/10.1097/ BRS.0000000000002154

22. Verhofste BP, Glotzbecker MP, Hresko MT, MacDougall RD, Birch $\mathrm{CM}, \mathrm{O}^{\prime} \mathrm{Neill} \mathrm{NP}$, et al. Intraoperative use of O-arm in pediatric cervical spine surgery. J Pediatr Orthop 2020;40:e266-71. https://doi. org/10.1097/BPO.0000000000001416

23. Mettler FA Jr, Huda W, Yoshizumi TT, Mahesh M. Effective doses in radiology and diagnostic nuclear medicine: a catalog. Radiology 2008;248:254-63. https://doi.org/10.1148/radiol.2481071451

24. Wilde F, Lorenz K, Ebner AK, Krauss O, Mascha F, Schramm A. Intraoperative imaging with a $3 \mathrm{D} \mathrm{C}$-arm system after zygomaticoorbital complex fracture reduction. J Oral Maxillofac Surg 2013; 71:894-910. https://doi.org/10.1016/j.joms.2012.10.031

25. Kurita M, Okazaki M, Ozaki M, Tanaka Y, Tsuji N, Takushima A, et al. Patient satisfaction after open reduction and internal fixation of zygomatic bone fractures. J Craniofac Surg 2010;21:45-9. https://doi.org/10.1097/SCS.0b013e3181c36304

How to cite this article: Peleg O, Ianculovici C, Shuster A, Mijiritsky E, Oz I, Kleinman S. Three-dimensional intraoperative computed tomography imaging for zygomatic fracture repair. J Korean Assoc Oral Maxillofac Surg 2021;47:382-387. https://doi. org/10.5125/jkaoms.2021.47.5.382 